\title{
Merger of Knowledge Network and Users Support for Lifelong Learning Services
}

\author{
Christian-Andreas Schumann, Claudia Tittmann and Sabine Tittmann \\ University of Applied Sc.Zwickau, PF 201037, 08012 Zwickau, Germany \\ schu@fh-zwickau.de; clt@fh-zwickau.de; sati@fh-zwickau.de \\ WWW home page: http://www.fh-zwickau.de
}

\begin{abstract}
Nowadays knowledge acquisition takes place in a lifelong process within diversified phases and styles. The complexity of knowledge transfer processes permanently increases. This specialization leads to the development of competence clusters and their intercross-linking to knowledge networks. It will be tried on the part of the knowledge acquisition to realize the knowledge transfer in a transparent and effective way by using high information density and high-grade knowledge representation. While the learning process itself and while using electronically learning- and knowledge transfer systems the learners will be supported by special services. Focus is on the process of interconnection and integration of levels, knowledge network and user support, in a useful and efficient way for mutual advantage. This process will be described in this paper.
\end{abstract}

\section{Diversity and Complexity of Knowledge Transfer}

In the past, the learning and knowledge transfer processes were much simpler and uncomplicated than today. With the development of the industrial and later information and knowledge society the information flood was augmented by new means of media permitting to transfer information in higher volumes and with higher density. At least, the half-life period of validity of the existing knowledge decreases continuously. Therewith the learning process became a life-long procedure with a lot of different kinds of learning objects, knowledge transfer methods, means and technologies as well as multimedia and computer aided information systems. Briefly worded a diverse and very complex network of methods, systems, and tools to control the efficient transfer of knowledge and information was generated.

The approach of knowledge management and learning procedures related to the required competencies is characterised by several views e.g. social view as network of the participating partners with diverse competencies, technical view as technology driven, and infrastructural development of competencies. The complexity will be augmented not only by the different views, subjects, and relations of the solving 
problem, but also by the required networks for the different kinds of services especially for knowledge sharing and transfer as well as knowledge workers and learners support [1].

\section{Genesis of Competence Clusters for Knowledge Sharing}

The growth of knowledge and competence is limited by the resources of the single organisation. Therefore, the development of networks of knowledge as well as networks of competence is forced by the scientific communities, the public organisations, and the private enterprises in order to generate the conditions for knowledge integration and sharing within the networks [2]. Knowledge management and engineering deal with the interconnectedness of particular information, and knowledge to complex, interconnected solutions in networks of competence. The competence networks and knowledge networks between organisations are precondition and enabler for knowledge transfer and knowledge sharing. In this context knowledge networks support inter-organisational cooperation and linking with external experts, associations, educational institutions for common knowledge application and diversification of the knowledge base [3]. Because of the ontological constitution of knowledge networks they are a suitable methodology for structuring, organising, and extending intra- and inter-organisational knowledge.

Knowledge sharing expatiates with the problem how to transfer collected knowledge into relevant organisational divisions and to initiate the lifelong learning process.

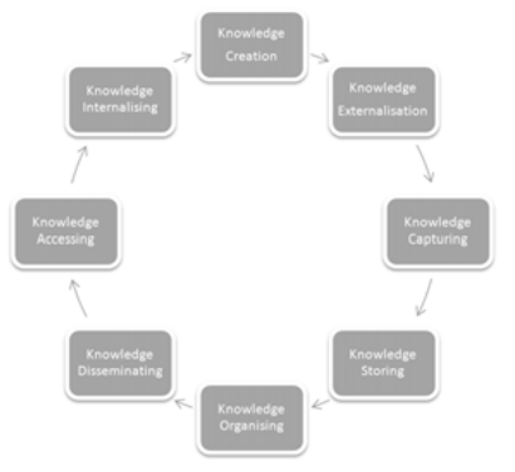

Fig. 1. Knowledge Sharing Lifecycle [4]

While the knowledge sharing lifecycle [3] the created knowledge will be externalised, structured, saved and organised. The knowledge base can be enhanced by external knowledge sources. Finally, this knowledge is - depending on authorisation - diffused inside the knowledge network and internalised by the users. This is premise for creating new knowledge and to continue or rather to iterate the lifecycle. For the creation of clusters of competence concepts the development of a knowledge base are necessary. Out of knowledge networks highly specialised competence and knowledge clusters can be developed and used for advancement of existing knowledge. Otherwise, existing competence clusters are able to be integrated into knowledge networks [1]. 


\section{Class of Learners and its Access to the Knowledge}

The ambition of a didactic strategy for e-learning is to arrange the learners to reach certain learning targets. However learners dispose of different attributes which aid or block the learning process [5]. Thus, the learners have to be classified [Fig1.].

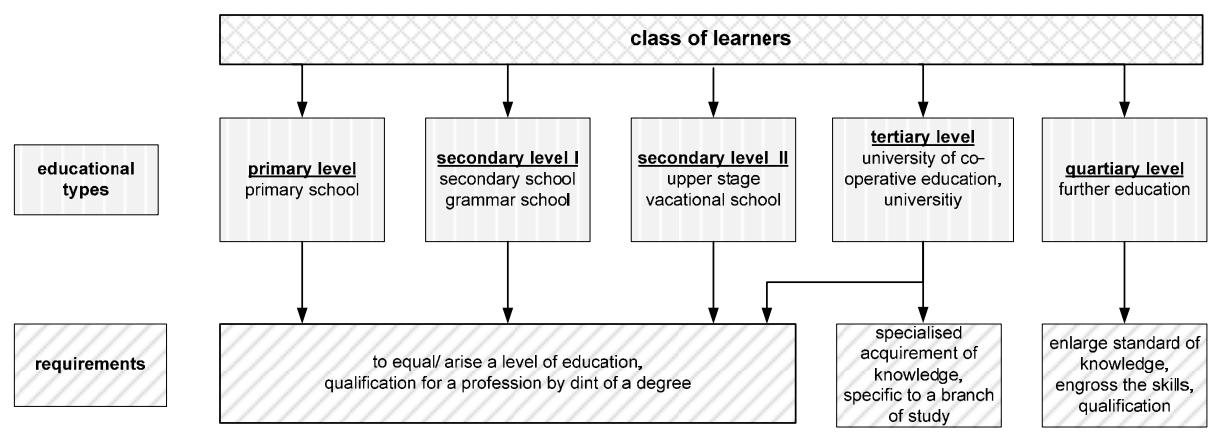

Fig. 2. Classification of Learners [6]

The requirements of learners of level schooling are basically consistent: own an equal level of education and get a qualification for a profession by dint of a degree. Learners of high level education aspire a specialised acquirement of knowledge by choosing a specific branch of study and by getting an academic degree. The level of further education includes lifelong learners, mostly learners in work life, who want to enlarge the standard of their knowledge. Concerning the previous knowledge, the learning contents have to be conceived according to this. [7] Another basic fact is the experiences with self-directed learning and the familiarity with diverse didactic methods or previous knowledge in diverse media. Different learners need different forms of learning instructions adjusted to their competencies. In all probability the scholars and first-year students are unversed in self-directed learning whereas students in higher semesters or active workers are able to deal with teaching material themselves. Homogeneity of learners eases the conception of the learning contents respectively the learning location [5]. All these described requirements of the learners provide a basis for requirements of an effective knowledge sharing. Ideally the learning content has to be developed in the level where it shall be used. Although the generated knowledge is available level comprehensive.

\section{Merger of Knowledge Worker's Supply and Learner's Demands}

A rough structuring in the framework of a systemic approach allows to pick up the main subsystems working together in order to provide the end user interface for e-education. Special main levels are essential for a successful, practical working of all the different kinds of systems and processes. They form a three level architecture for application of e-education.

The first level is composed of the e-platforms, computer-based training and webbased training systems, etc. as a first level backbone network from the users view. 
The second level cooperation network is formed by the e-education specialists pushing the development and application of e-learning in the framework of competence clusters. The third level support network is characterised as user's support network including the personal services for the end users. Therefore, it is necessary to develop a special tutoring and coaching system. For this purpose experiences and knowledge of e-learning specialists are fundamental. All the experiences have to be assembled to one tutoring system which helps the learners in getting basic principles and particularly avoids typical beginner's mistakes of elearning. The practical realisation is multi-level organised and contains primarily a presentation of good practice examples, guided computer applications and e-learning basics. With those competencies the learners of all categories have a boundless approach to the knowledge and they are qualified for lifelong learning. It is also important to ensure a permanent information flow between specialists and learners organisational as well as technological in use of the e-learning platform. Thus, it is possible to integrate all levels to one consistently standard and assure knowledge sharing among the universities and beyond it. [8]

To realise a transparent and effective knowledge transfer, specialised competence and knowledge clusters have to be developed and linked to knowledge networks. Learners of all classes will be supported by special tutoring and coaching systems to have a boundless approach to these networks and therewith practice knowledge transfer while using electronically learning- and knowledge transfer systems. This offers the opportunity of lifelong learning to young and adult learners.

\section{References}

1. C.A. Schumann, C. Tittmann, Multilevel Cross-Linking and Offering of Organisational Knowledge. In: Martins, B., Remenyi, D.: Proceedings of the 8th European Conference on Knowledge Management (Volume Two). Barcelona. Reading: Academic Conferences. 2007. 878883. (ISBN: 978-905305-52-0)

2. C.A. Schumann, C. Tittmann, J. Weber, E-Education Competence Cluster as Knowledge Transfer Hub in a Multilayer Architecture; Proceedings IT Towards Empowerment (ITE) International Conference 2007, Bangkok/Thailand, 2007.

3. M. Haun, Handbuch Wissensmanagement, Springer Verlag, Berlin/Heidelberg, 2002.

4. F. Kappe, Knowledge Management with the Hyperwave eKnowledge Infrastructure, White Paper, Hyperwave, 2001.

5. S. Walter, Blended Learning in der Hochschullehre, Rudolf Haufe Verlag, Freiburg i. Br., 2007.

6. Hochschule Zittau/ Görlitz (FH), Fachbereich Sprachen (March, 27, 2008); http://www.hszigr.de/ bgriebel/bildungswesen.gif, Quelle: Zahlenbarometer vom Bundesministerium für Bildung und Wissenschaft

7. M. Kerres, Multimediale und telemediale Lernangebote - Konzeption und Entwicklung, Oldenbourg Verlag, München, Wien, 1998.

8. C.A. Schumann, S. Tittmann, current results of research work in project "multilevel approach for last-mile-solutions supported by e-education competence clusters" at Zwickau university, 2007, 2008. 